Research Article

\title{
Operation Strategies Based on Horizontal Competition and Service Capability Sharing under Demand Disturbance
}

\author{
Kun Wang $\mathbb{D i D}^{1}$ and Dongsong $\mathrm{Wu} \mathbb{i D}^{2}$ \\ ${ }^{1}$ School of Business, Nankai University, Tianjin 300071, China \\ ${ }^{2}$ School of Economics, Tianjin University of Finance and Economics, Tianjin 300222, China \\ Correspondence should be addressed to Dongsong Wu; wudongsong126@126.com
}

Received 6 November 2020; Revised 23 December 2020; Accepted 29 December 2020; Published 13 January 2021

Academic Editor: Maria Alessandra Ragusa

Copyright (c) 2021 Kun Wang and Dongsong Wu. This is an open access article distributed under the Creative Commons Attribution License, which permits unrestricted use, distribution, and reproduction in any medium, provided the original work is properly cited.

\begin{abstract}
The article considers the influence of demand disturbance on price, service capability, and operation mode selection of firms. Firstly, we discuss the equilibrium pricing and service capability strategy of the firm under three operation modes: price and service competition, price competition and service capability sharing, and price and service centralized making-decision. When there is demand disruption, firms determine their pricing and service capacity strategies under the three main operating models above. Finally, the comparative analysis shows that the influence of service capability in centralized decision price and service capability mode is greater than that on service capability in price competition and service capability sharing mode. The smoothness of service capability in price competition and service capability sharing mode is better than that in the centralized decision mode. And when the market price competition coefficient is moderate or the negative demand disturbance occurs, the price competition and service capability sharing mode has little influence on the profit compared with the other two modes (the profit loss is the smallest).
\end{abstract}

\section{Introduction}

The global outbreak of the COVID-19 in 2019 caused many industries' supply chains to be interrupted, and demand was greatly disturbed. The United States unilaterally provoked a trade dispute in 2018. After placing Huawei and 70 affiliated firms on the US "entity list." Huawei supply chain and domestic industrial supply chain security were pushed to the forefront. Faced with US sanctions, the supply chain of firms represented by Huawei has a great impact. Behind these demand disturbances, there is a severe test of the service capability of the firm. In the face of the demand disturbance caused by unpredictable factors (culture, politics, and social trends), how should a service firm make a better decision to expand its service capability (when the disturbance does not exist) or fight a price war with its competitors? That is the concern of this article.

Because of the great influence of unpredictable disturbance events on the production and operation of the core firms in the supply chain, many experts and scholars have carried out in-depth research on the disturbance coordination of the product supply chain. Clausen et al. [1] first put forward the concept of "interrupt management" and applied it to the successful management routes. Lan et al. [2] proposed a two-stage interference management model and gave the corresponding ant colony algorithm to solve the problem of demand disturbance. On the premise that demand is a linear function of price, Cao et al. [3] study the pricing and production decision of supply chain members when demand and cost are disturbed together and gives the optimal pricing and production decision of the supply chain in different disturbance ranges. The equilibrium model of the supply chain network is constructed by using variational inequality, which shows that supply chain members need to make new production and sales plans after demand disturbance. Supply chain demand disruption management is due to the complexity and dynamics of the supply chain environment [4-6]. In order to manage the supply chain more effectively, 
it is necessary to pay attention to the real interruption risk [7]. Generally, the most interruptions supply chain can be divided into three types: demand-related, supply-related, and other [8]. Demand disruption is the risk of unexpected changes and sharp increases or decreases in demand.

When unpredictable events occur in the supply chain, they are transmitted directly to the demand side, and the demand disturbance makes some firms in trouble. Therefore, some scholars put forward the supply chain coordination based on the demand disturbance. Li et al. [9] and others studied the decision-making of the recycling and remanufacturing cycle of waste products in a closed-loop supply chain. Considering the demand disturbance, the members of the closed-loop supply chain determine whether to deal with the demand disturbance through the coordination strategy of quantity discount contract and pricing contract according to the degree of disturbance. Cao et al. [10] and others proposed that the improved revenue-sharing contract should be used to coordinate the demand disturbance of the manufacturer's dual-channel supply chain. When manufacturing and demand are interrupted, Pi et al. [11] use volume discount contracts to coordinate supply chains that include one manufacturer and two competing retailers. Chen and Xiao [12] discuss how to use quantity discount contracts or wholesale price contracts to manage the supply chain, including a common supplier, a major retailer, and several complementary retailers. Zhang et al. [13] demonstrate that revenue-sharing contracts can coordinate supply chains involving manufacturers and two retailers after demand breaks. Cao et al. [3] note how revenuesharing contracts are used to complete supply chain coordination with a single manufacturer and several Cournot competing retailers when demand and costs are interrupted simultaneously?

At present, the study of demand interruption usually considers one-to-one and one-to- $\mathrm{N}$ supply chain structures. $\mathrm{Xu}$ et al. [14] studied how to deal with demand interruptions in a supply chain consisting of a supplier and a retailer and set the demand as a nonlinear function. In one-to-one structure, supply chains with one-to- $\mathrm{N}$ structures are discussed in demand interrupt management. Chen et al. [15] seek to coordinate supply chain disruptions involving single vendors and several independent retailers. On this basis, Chen and Xiao [16] and Qiu-Lei et al. [17] discuss pricing and complementary strategies, as well as interrupt systems with several competitive retailers. Schmitt et al. [18] developed a supply chain model consisting of two competitive retailers with promotional investment rights and sensitive demand. Xiao and $\mathrm{Yu}$ [19] studied the steady evolution of duopoly competition in supply chains, in which two retailers sold similar products. Rahmani and Yavari [20] established a supply chain including the manufacturer and two competing retailers, with linear and unit quantity discount mechanism, to coordinate the supply chain after the disruption of demand and analyzed the two situations of product cost variation and product cost variation undertaken by retailers. A two-phase price and production model of the supply chain is constructed through two distribution channels, and how to adjust the price and production plan when demand is interrupted [21]. These literature consider the problem of supply chain coordination under horizontal competition or demand disturbance, and most of their focus is on the manufacturing firm; as the contribution of service firms in GDP increases, the role of service industry becomes more and more important. This paper mainly focuses on how to coordinate and compete with the operation strategy of service supply chain core firms in the face of horizontal competition and demand disturbance.

When demand is disturbed, the influence of firms in the service supply chain is very large. Few previous literature studied that the horizontal competition and demand disturbance do not consider service supply chain. Firstly, the equilibrium pricing and service capability strategy of the firm under three main operating modes are discussed when there is no demand disturbance. Secondly, when there is demand disturbance, firm balance pricing and service capability strategy under three main operating modes. Finally, the comparative analysis and numerical analysis are carried out to verify the relevant conclusions, and the influence of different parameters on the optimal operation strategy selection of the competitive firm is further analyzed.

\section{Model Building and Assumptions}

This paper uses the Nash game to study the supply chains of only two service firm competing horizontally. Demand function of horizontal competitors is $d_{i}=a-p_{i}+\beta p_{j}+\gamma s_{i}-\varphi s_{j}$. Horizontal competitors' profit function is $\pi_{i}\left(p_{i}, s_{i}\right)=p_{i}\left(a-p_{i}+\beta p_{j}+\gamma s_{i}-\varphi s_{j}\right)-k_{i} s_{i}^{2} / 2$. $p_{i}$ and $p_{j}$ are the retail price of competitor $i, j$ unit products. $s_{i}$ and $s_{j}$ are competitors' service ability, and $d_{i}$ and $d_{j}$ are the competitors' demand. $a$ is market capability. $\beta$ is the price competition coefficient. $\gamma$ and $\varphi$ are the service demand elasticity, and $k_{i}$ and $k_{j}$ are the service cost coefficient of competitors. Define " $N$ " for the price and service competition mode (no service capability sharing). "S" stands for price competition and service capability sharing model (shared service capability). " $C$ " represents the pricing and service centralization decision pattern (shared service capability). "*” is used to indicate the optimal value of the variable, and " $\sim$ " is used to indicate the disturbance of the requirement. The optimal decision of competitors under different modes is shown in Tables 1 and 2 .

\section{No Demand Disturbance}

In order to ensure the equilibrium decision-making of competitors, this section makes the following constraint assumptions for basic parameters as follows: $2 k_{1}>\gamma^{2}$ and $(1-\beta) k_{1}>(\gamma-\varphi)^{2}$. At the same time, we denote $A=\left(-\gamma^{2}-\gamma \varphi+2 k_{2}+\beta k_{2} /\left[\gamma^{2}\left(\varphi^{2}+2 k_{1}+2 k_{2}-\gamma^{2}\right)+\left(\beta^{2}-\right.\right.\right.$ $\left.\left.4) k_{1} k_{2}-\beta \gamma \varphi\left(k_{1}+k_{2}\right)\right]\right)<0$ and $B=(2+\beta)\left(k_{1}(2-\right.$ $\left.\beta)-(\gamma-\varphi)^{2}\right)$.

3.1. Price and Service Competition Model (No Service Sharing). In the context of price and service competition, two competitors have price competition and service ability competition. In the process of the game, two competitors make 
TABLE 1: Equilibrium prices and service capability without demand disturbances.

\begin{tabular}{lcc}
\hline & Price & Service capability \\
\hline 3.1 & $p_{1}^{N^{*}}=-a k_{1} A p_{2}^{N^{*}}=-a k_{2} A$ & $s_{1}^{N^{*}}=-a \gamma A s_{2}^{N^{*}}=-a \gamma A$ \\
3.2 & $\left.p_{2}^{S^{S^{*}}=\left((2+\beta)\left(p_{r}(\gamma-\varphi)^{2}+a k_{1}\right)+3 \beta k_{1} p_{r} / B\right)}(2 \beta+1)(\gamma-\varphi)^{2}+k_{1}\left(p_{r}\left(2+\beta^{2}\right)+a(2+\beta)\right) / B\right)$ & $s_{1}^{S^{*}}=\left(\left(2 a+4 p_{r}+a \beta+3 \beta p_{r}-\beta^{2} p_{r}\right)(\gamma-\varphi) / B\right)$ \\
\hline 3.3 & $p_{1}^{C^{*}}=a k_{1} / 2(1-\beta) k_{1}-2(\gamma-\varphi)^{2}$ \\
$p_{2}^{C^{*}}=a k_{1} / 2(1-\beta) k_{1}-2(\gamma-\varphi)^{2}$ & $s_{1}^{C^{*}}=a(r-\varphi) /(1-\beta) k_{1}-(\gamma-\varphi)^{2}$ \\
\hline
\end{tabular}

their own pricing and service ability at the same time, in order to expect to maximize their profits. The profit function of both parties is as follows:

$$
\begin{aligned}
& \operatorname{Max} \pi_{1}\left(p_{1}, s_{1}\right)=p_{1} d_{1}-\frac{k_{1} s_{1}^{2}}{2}, \\
& \operatorname{Max} \pi_{2}\left(p_{2}, s_{2}\right)=p_{2} d_{2}-\frac{k_{2} s_{2}^{2}}{2} .
\end{aligned}
$$

Based on the principle of profit maximization, the Hessian matrix of $\pi_{1}\left(p_{1}, s_{1}\right)$ and $\pi_{2}\left(p_{2}, s_{2}\right)$ are $H_{1}=\left[\begin{array}{cc}-2 & \gamma \\ \gamma & -k_{1}\end{array}\right]$ and $H_{2}=\left[\begin{array}{cc}-2 & \gamma \\ \gamma & -k_{2}\end{array}\right]$. When $\left|H_{1}\right|=2 k_{1}-$ $\gamma^{2}>0$ and $\left|H_{2}\right|=2 k_{2}-\gamma^{2}>0$, there is an optimal decision of profit maximization between the two competitors. Therefore, the Nash equilibrium solution of competitors can be obtained from $\left(\partial \pi_{1}\left(p_{1}, s_{1}\right) / \partial p_{1}\right)=0,\left(\partial \pi_{1}\left(p_{1}, s_{1}\right) / \partial s_{1}\right)=0$, $\left(\partial \pi_{2}\left(p_{2}, s_{2}\right) / \partial p_{2}\right)=0$, and $\left(\partial \pi_{2}\left(p_{2}, s_{2}\right) / \partial s_{2}\right)=0$. Competitors have optimal solutions (see Table 1$)$.

The comparative analysis shows that the relative price and service ability of the two competitors depend on the service cost coefficient of the competitors. When $k_{1}>k_{2}$, you can get $p_{1}^{N^{*}}>p_{2}^{N^{*}}$ and $s_{1}^{N^{*}}>s_{2}^{N^{*}}$ otherwise, then $p_{1}^{N^{*}} \leq p_{2}^{N^{*}}$ and $s_{1}^{N^{*}} \leq s_{2}^{N^{*}}$. When competitor 1 has a higher service cost coefficient that means competitor 1 needs to bear higher service costs when providing the same service capacity as competitor 2. So, for competitor 1 , setting higher retail prices and improving their service capacity can grab more profit space.

\subsection{Price Competition and Service Capability Sharing Model} (Shared Service Capability). In the context of price competition and service capacity sharing, two competitors have price competition, but because of the existence of service capacity sharing, the service capacity of the two competitors is the same, whether competitors 1(2) share their own service capacity. The optimal decision is dual. Competitor 1 chooses to share its own service capabilities, and competitor 2 will purchase $d_{2}$ services $\left(s_{2}=s_{1}\right)$ from competitor 1 by $p_{r}$. In the process of the game, two competitors make their own decision variables at the same time, competitor 1 makes its own pricing and service ability, and competitor 2 makes its own pricing in order to maximize their profits. The profit function of both parties is as follows:

$$
\begin{aligned}
\operatorname{Max} \pi_{1}\left(p_{1}, s_{1}\right) & =p_{1} d_{1}+p_{r} d_{2}-\frac{k_{1} s_{1}^{2}}{2} \\
\operatorname{Max} \pi_{2}\left(p_{2}\right) & =\left(p_{2}-p_{r}\right) d_{2} .
\end{aligned}
$$

The proof process of 3.2 is similar to that of 3.1, so we will not repeat it. It can be found that the price and service ability of competitors are directly proportional to the price $\left(p_{r}\right)$ of the service ability of competitor 2 to purchase 1 . With the increase in price $\left(p_{r}\right)$, the cost of competitor 2 increases. In order to guarantee its profit margin, the retail price needs to be raised. For competitor 1, the price of purchasing its service capacity is increased, and the best decision is to improve its service capacity and retail price in order to gain a larger market and gain a greater profit.

3.3. Model for Centralized Decision-Making on Price and Service Capability (Shared Service Capability). In the context of centralized decision-making price and service capability, the pricing and service capability decisions of competitor $1 / 2$ are centralized decisions, but because of the existence of service capability sharing, the service capabilities of the two competitors are the same. Whether competitor 1(2) shares its service capability, optimal decision is dual. Competitor 1 chooses to share its own service capabilities, and competitor 2 will purchase $d_{2}$ services $\left(s_{2}=s_{1}\right)$ from competitor 1 by $p_{r}$. In the process of the game, centralized decision-making simultaneously determines the price and service ability of the two competitors in order to achieve the maximum profit in the centralized situation. The profit function under the centralized decision is as follows:

$$
\begin{aligned}
\pi_{1}\left(p_{1}, s_{1}\right) & =p_{1} d_{1}+p_{r} d_{2}-\frac{k_{1} s_{1}^{2}}{2}, \\
\pi_{2}\left(p_{2}\right) & =\left(p_{2}-p_{r}\right) d_{2}, \\
\operatorname{Max} \pi\left(p_{1}, p_{2}, s_{1}\right) & =\pi_{1}\left(p_{1}, s_{1}\right)+\pi_{2}\left(p_{2}\right) .
\end{aligned}
$$

The proof process of 3.3 is similar to that of 3.1, so we will not repeat it. It can be found that the retail price, is consistent. And both retail price and service capability have nothing to do with the price $\left(p_{r}\right)$ of the service capability of competitor 2 to buy competitor 1s'. 
TABLE 2: Equilibrium prices and service capability with demand disturbances.

\begin{tabular}{|c|c|c|}
\hline & Price & Service capability \\
\hline 4. 1 & $\tilde{p}_{1}^{N *}=-k_{1} C \tilde{p}_{2}^{N *}=-k_{2} C$ & $\tilde{s}_{1}^{N *}=-\gamma C \widetilde{s}_{2}^{N *}=-\gamma C$ \\
\hline 4. 2 & $\begin{array}{c}\tilde{p}_{1}^{S *}=\left((2+\beta)\left(p_{r}(\gamma-\varphi)^{2}+k_{1}(a+\Delta a)\right)+3 \beta p_{r} k_{1} / B\right) \\
\tilde{p}_{2}^{S *}=\left(p_{r}(2 \beta+1)(\gamma-\varphi)^{2}+p_{r} k_{1}\left(2+\beta^{2}\right)+\right. \\
\left.k_{1}(2+\beta)(a+\Delta a) / B\right)\end{array}$ & $\widetilde{s}_{1}^{S *}=\left(\left((2+\beta)(a+\Delta a)+4 p_{r}+\beta p_{r}(3-\beta)\right)(\gamma-\varphi) / B\right)$ \\
\hline 4. 3 & $\begin{array}{l}\tilde{p}_{1}^{C *}=(a+\Delta a) k_{1} / 2(1-\beta) k_{1}-2(\gamma-\varphi)^{2} \\
\widetilde{p}_{2}^{C *}=(a+\Delta a) k_{1} / 2(1-\beta) k_{1}-2(\gamma-\varphi)^{2}\end{array}$ & $\widetilde{s}_{1}^{C *}=(a+\Delta a)(r-\varphi) /(1-\beta) k_{1}-(\gamma-\varphi)^{2}$ \\
\hline
\end{tabular}

\section{With Demand Disturbances}

In business practice, many uncertain factors may frequently disrupt demand and cause demand to fluctuate. Once a demand disturbance occurs, supply chain members may change their decisions to keep their profits at relatively high levels. The demand function of the horizontal competitor is $d_{i}=a+\Delta a-p_{i}+\beta p_{j}+\gamma s_{i}-\varphi s_{j}$. The profit function of the horizontal competitor is $\pi_{i}\left(p_{i}, s_{i}\right)=p_{i}\left(a+\Delta a-p_{i}+\beta p_{j}+\right.$ $\left.\gamma s_{i}-\varphi s_{j}\right)-k_{i} s_{i}^{2} / 2$, which the demand disturbance $\Delta a$ is represented. Therefore, the competitor's demand function is

$$
\begin{aligned}
& d_{1}=a+\Delta a-p_{1}+\beta p_{2}+\gamma s_{1}-\varphi s_{2}, \\
& d_{2}=a+\Delta a-p_{2}+\beta p_{1}+\gamma s_{2}-\varphi s_{1} .
\end{aligned}
$$

Denote: $C=\left((a+\Delta a)\left(-\gamma^{2}-\gamma \varphi+2 k_{2}+\beta k_{2}\right) /\left[\gamma^{2}\left(\varphi^{2}+\right.\right.\right.$ $\left.\left.\left.2 k_{1}+2 k_{2}-\gamma^{2}\right)+\left(\beta^{2}-4\right) k_{1} k_{2}-\beta \gamma \varphi\left(k_{1}+k_{2}\right)\right]\right)<0$.

\subsection{Price and Service Competition Model (No Service Sharing).} In the context of price and service competition, two competitors have price competition and service ability competition. The profit function of both parties under the disturbance of demand is as follows:

$$
\begin{aligned}
& \operatorname{Max} \pi_{1}\left(p_{1}, s_{1}\right)=p_{1} d_{1}-\frac{k_{1} s_{1}^{2}}{2}, \\
& \operatorname{Max} \pi_{2}\left(p_{2}, s_{2}\right)=p_{2} d_{2}-\frac{k_{2} s_{2}^{2}}{2} .
\end{aligned}
$$

The impact of demand disturbance $(\Delta a)$ on competitors' prices and service capability is in the same direction. If some factors lead to positive demand disturbance, that is, the expansion of market share (the Japanese earthquake nuclear leakage led to the increase of iodized salt market), the best decision from competitors themselves is to increase prices and service capability to make greater profits; if unexpected factors lead to the reduction of original market share $(\Delta a<0)$, competitors choose to reduce prices and service capability in order to maintain their market position and profit space.

4.2. Price Competition and Service Capability Sharing Model (Shared Service Capability). In the context of price competition and service capability sharing under demand disturbance, the profit functions of both parties are as follows:

$$
\begin{aligned}
\operatorname{Max} \pi_{1}\left(p_{1}, s_{1}\right) & =p_{1} d_{1}+p_{r} d_{2}-\frac{k_{1} s_{1}^{2}}{2} \\
\operatorname{Max}_{2}\left(p_{2}\right) & =\left(p_{2}-p_{r}\right) d_{2}
\end{aligned}
$$

The price and service capability of competitors can be found to be positive proportional to the price $\left(p_{r}\right)$ and demand disturbance $(\Delta a)$ of the service capability purchased by competitor 2 . As the cost increases, the retail price of competitor 2 needs to be increased to ensure its profit margin. For competitor 1, the price of purchasing its service capability increases, and the best decision is to improve its service capability and retail price to get a bigger market and grab a bigger profit.

4.3. Model of Centralized Decision-Making Price and Service Capability (Shared Service Capability). In the case of centralized decision price and service ability decision of demand disturbance, the profit function under centralized decision is as follows:

$$
\begin{aligned}
\pi_{1}\left(p_{1}, s_{1}\right) & =p_{1} d_{1}+p_{r} d_{2}-\frac{k_{1} s_{1}^{2}}{2}, \\
\pi_{2}\left(p_{2}\right) & =\left(p_{2}-p_{r}\right) d_{2}, \\
\operatorname{Max} \pi\left(p_{1}, p_{2}, s_{1}\right) & =\pi_{1}\left(p_{1}, s_{1}\right)+\pi_{2}\left(p_{2}\right) .
\end{aligned}
$$

We can find the same retail price for competitors, and both retail price and service capability have nothing to do with the price $\left(p_{r}\right)$ of the service capability of competitor 2 to buy 1 . The impact of demand disturbance $(\Delta a)$ on competitors' prices and service capability is in the same direction.

\section{Comparative Analysis}

Proposition 1. Under the mode of price competition and service capability sharing, we compare the optimal solutions of competitors 1 and 2. When demand disturbance occurs, the change of retail price and service capability and demand disturbance $(\Delta a)$ is in the same direction. 


$$
\begin{aligned}
& \Delta p_{1}^{N *}=\widetilde{p}_{1}^{N *}-p_{1}^{N *}=-k_{1} \Delta a A, \\
& \Delta p_{2}^{N *}=\widetilde{p}_{2}^{N *}-p_{2}^{N *}=-k_{2} \Delta a A, \\
& \Delta s_{1}^{N *}=\widetilde{s}_{1}^{N *}-s_{1}^{N *}=-\gamma \Delta a A, \\
& \Delta s_{2}^{N *}=\widetilde{s}_{2}^{N *}-s_{2}^{N *}=-\gamma \Delta a A .
\end{aligned}
$$

If unexpected factors lead to positive disturbance of demand $(\Delta a>0)$, the potential market demand expands at this time, the two competitors take measures to raise retail prices in order to grab higher profits, and in order to consolidate the market position will improve their service capability. If adverse market factors lead to negative disturbance of demand $(\Delta a<0)$, both competitors will take conservative measures to reduce prices and promote sales to consolidate the market position, while reducing service capability and reducing costs.

Proposition 2. For competitor 2, the impact of demand disturbance on its retail price and service capability is consistent with that of competitor 1 . When demand disturbance occurs, the change of retail price and service capability and demand disturbance $(\Delta a)$ change are in the same direction for competitor 1 .

$$
\begin{aligned}
& \Delta p_{1}^{S *}=\widetilde{p}_{1}^{S *}-p_{1}^{S *}=\frac{k_{1} \Delta a}{k_{1}(2-\beta)-(\gamma-\varphi)^{2}}, \\
& \Delta p_{2}^{S *}=\widetilde{p}_{2}^{S *}-p_{2}^{S *}=\Delta p_{1}^{S *}, \\
& \Delta s_{1}^{S *}=\widetilde{s}_{1}^{S *}-s_{1}^{S *}=\frac{\Delta a(\gamma-\varphi)}{k_{1}(2-\beta)-(\gamma-\varphi)^{2}} .
\end{aligned}
$$

If unexpected factors lead to positive disturbance of demand $(\Delta a>0)$, the potential market demand expands; at this time, the two competitors take measures to raise retail prices in order to grab higher profits. Meanwhile, in order to consolidate the market position, they will improve their service capability.

Proposition 3. When demand disturbance occurs, for competitor 1(2), the changes trend of retail price and service capability are the same as demand disturbance $(\Delta a)$ change trend.

$$
\begin{aligned}
& \Delta p_{1}^{C *}=\widetilde{p}_{1}^{C *}-p_{1}^{C *}=\frac{k_{1} \Delta a}{2(1-\beta) k_{1}-2(\gamma-\varphi)^{2}}, \\
& \Delta p_{2}^{C *}=\widetilde{p}_{2}^{C *}-p_{2}^{C *}=\Delta p_{1}^{C *}, \\
& \Delta s_{1}^{C *}=\widetilde{s}_{1}^{C *}-s_{1}^{C *}=\frac{\Delta a(r-\varphi)}{(1-\beta) k_{1}-(\gamma-\varphi)^{2}} .
\end{aligned}
$$

Proposition 4. Analysis of the influence of demand disturbance on price competition and service capability sharing mode and centralized decision price and service capability mode.

$$
\begin{aligned}
& \frac{\mathrm{d} \widetilde{p}_{1}^{C *}}{\mathrm{~d} \Delta a}=\frac{\mathrm{d} \widetilde{p}_{2}^{C *}}{\mathrm{~d} \Delta a}=\frac{k_{1}}{2(1-\beta) k_{1}-2(\gamma-\varphi)^{2}}, \\
& \frac{\mathrm{d} \widetilde{p}_{1}^{S *}}{\mathrm{~d} \Delta a}=\frac{\mathrm{d} \widetilde{p}_{2}^{S *}}{\mathrm{~d} \Delta a}=\frac{k_{1}}{k_{1}(2-\beta)-(\gamma-\varphi)^{2}}, \\
& \frac{\mathrm{d} \widetilde{p}_{1}^{C *}}{\mathrm{~d} \Delta a}=\frac{\mathrm{d} \widetilde{p}_{2}^{C *}}{\mathrm{~d} \Delta a}>\frac{\mathrm{d} \widetilde{p}_{1}^{S *}}{\mathrm{~d} \Delta a}=\frac{\mathrm{d} \tilde{p}_{2}^{S *}}{\mathrm{~d} \Delta a} .
\end{aligned}
$$

According to Proposition 4, it can be found that the influence of demand disturbance on price in centralized decision price and service ability mode are greater than that on price competition and service capability sharing mode. Price competition and service capability sharing mode of prices relative to centralized decision-making mode is more stable. If demand disturbances often occur, price competition and service capability sharing models are more advantageous in stabilizing prices.

Proposition 5. An analysis of the impact of demand disturbance on service capability under price competition and service capability sharing mode and centralized decisionmaking price and service capability mode is as follows:

$$
\begin{aligned}
& \frac{\mathrm{d} \widetilde{s}_{1}^{C *}}{\mathrm{~d} \Delta a}=\frac{(\gamma-\varphi)}{k_{1}(1-\beta)-(\gamma-\varphi)^{2}}, \\
& \frac{\mathrm{d} \widetilde{s}_{1}^{S *}}{\mathrm{~d} \Delta a}=\frac{(\gamma-\varphi)}{k_{1}(2-\beta)-(\gamma-\varphi)^{2}}, \\
& \frac{\mathrm{d} \widetilde{s}_{1}^{C *}}{\mathrm{~d} \Delta a}>\frac{\mathrm{d} \widetilde{s}_{1}^{S *}}{\mathrm{~d} \Delta a}
\end{aligned}
$$

Similarly to Proposition 5, it can be found that the effect of demand disturbance on service capability in centralized decision price and service capability mode is greater than that in price competition and service capability sharing mode. If demand disturbance occurs, the smoothness of service capability in price competition and service capability sharing mode is better than centralized decision mode. If demand disturbances often occur, the price competition and service capability sharing model will have more advantages in stabilizing service capability, stabilizing the reputation of its competitors, and making service capability more stable.

\section{Numerical Analysis}

The influence of exogenous parameters such as horizontal competition coefficient $\beta$ and demand disturbance $\Delta a$ on the decision of supply chain members under different modes is studied. "Model1," "Model2," and "Model3" are price and service competition, price competition and service capability sharing, and price and service centralized decision-making mode, respectively.

6.1. Impact of Competitive Price Intensity on Competitors' Profits. The influence of demand disturbance on 
competitor's profit is studied by numerical analysis. The specific parameters are as follows:

$$
\begin{aligned}
a & =100, \\
\gamma & =0.5, \\
\varphi & =0.4, \\
k_{1} & =3, \\
k_{2} & =2, \\
p_{r} & =15 .
\end{aligned}
$$

Figures 1 and 2 show that when considering the positive and negative demand disturbance, the influence of market price competition intensity on competitor 1's profit is analyzed numerically. According to the numerical analysis results, whether the demand disturbance is positive or negative, competitor 1's profit changes in the same direction as the market price competition coefficient in three different modes. When the market price competition coefficient is relatively small and large, that is, when the market price competition is not fierce or very fierce, the profit space brought by the centralized decision to competitor 1 is greater. But when the market price competition coefficient is moderate, the price competition and service ability sharing model are more attractive to competitors, which is a very interesting conclusion. The value created by service ability sharing is better than centralized decision making in some cases.

Figures 3 and 4 show that when positive and negative demand disturbances are considered, the effect of market price competition intensity on the profit of competitor 2 is analyzed numerically; the conclusion is similar to that of Figures 1 and 2. According to the numerical analysis results, whether the demand disturbance is positive or negative, the profit of competitor 2 changes in the same direction as the market price competition coefficient in three different modes. When the market price competition coefficient is relatively small and large, that is, when the market price competition is not fierce or very fierce, the profit space brought by the centralized decision to competitor 2 is greater. But when the market price competition coefficient is moderate, the price competition and service ability sharing model are more attractive to competitors, which is a very interesting conclusion. It also shows that the value created by service ability sharing is better than centralized decision making in some cases.

6.2. Impact of Demand Disturbances on Competitors' Profits. The influence of demand disturbance on a competitor's profit is mainly studied by numerical analysis. The values of specific parameters are basically the same as those of 6.1 as follows:

$$
\begin{aligned}
a & =100, \\
\beta & =0.5, \\
\gamma & =0.5, \\
\varphi & =0.4, \\
k_{1} & =3, \\
k_{2} & =2, \\
p_{r} & =15, \\
\Delta a & =-100: 1: 100 .
\end{aligned}
$$

Figure 5 shows that $\Delta a$ has the impact on competitor 1's profit. It can be seen that when a large negative and positive demand disturbance occurs, the centralized decision price and service capability model have a slightly smaller impact on competitor 1's profit than the other two models. At this point, competitor 1 has the smallest profit loss in the centralized decision-making mode. In comparison, competitor 1 will choose the centralized decision-making mode, and the greater the positive disturbance, the more obvious the advantage of centralized decision-making will be. However, when a relatively small negative demand disturbance occurs, the price competition and service capability sharing model have a slightly smaller impact on the profits than the other two models. Competitor 1 has the smallest profit loss under the mode of price competition and service capability sharing. Comparatively speaking, competitor 1 chooses price competition and service capability sharing mode. This is an interesting conclusion. In general, the situation in centralized decision making is slightly better than that in the other two decentralized decisions, but the mode of price competition and service capability sharing is better than that in centralized decision making.

Figure 6 shows the impact on the profit of competitor 2 . It can be seen that when a large negative and positive demand disturbance occurs, the centralized decision price and service capability model have a slightly smaller impact on the profit of competitor 2 than the other two models. At this point, competitor 2 has the smallest profit loss in the centralized decision-making mode. In comparison, competitor 2 will choose the centralized decision-making mode, and the greater the positive disturbance, the more obvious the advantage of centralized decision-making will be. However, when a relatively small negative demand disturbance occurs, the price competition and service capability sharing model have a slightly smaller impact on the profits than the other two models. Competitor 2 has the smallest profit loss under the mode of price competition and service capability sharing. Comparatively speaking, competitor 2 will choose price competition and service capability sharing mode. This is an interesting conclusion. In general, the situation in centralized decision-making is slightly better than the other two decentralized decision-making situations, but the price 


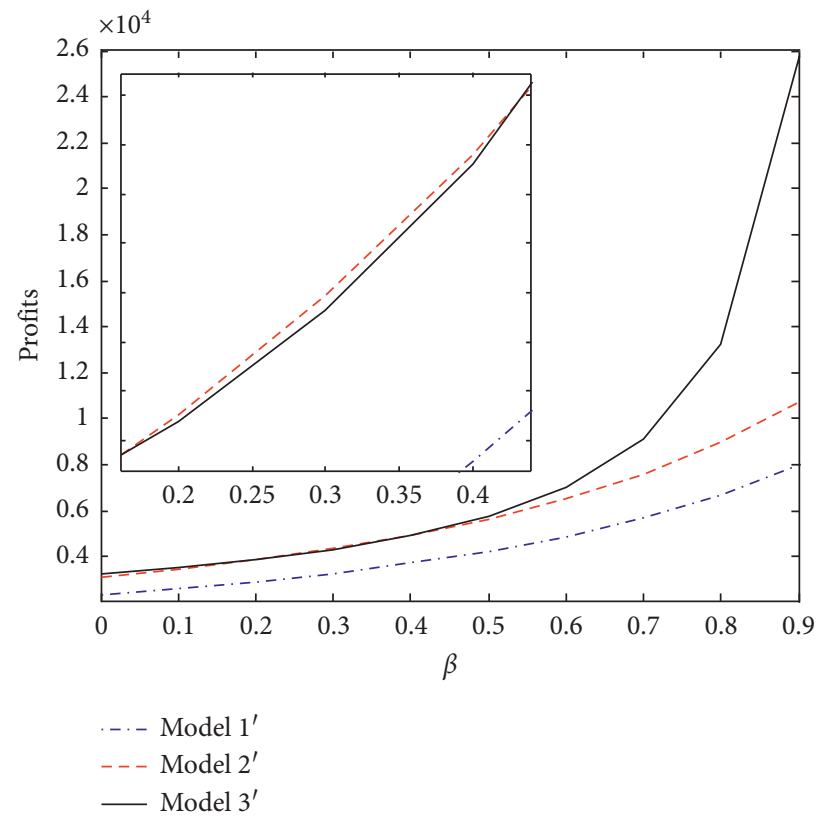

Figure 1: The effect of $\beta$ on competitor1's profit $(\Delta a=50)$.

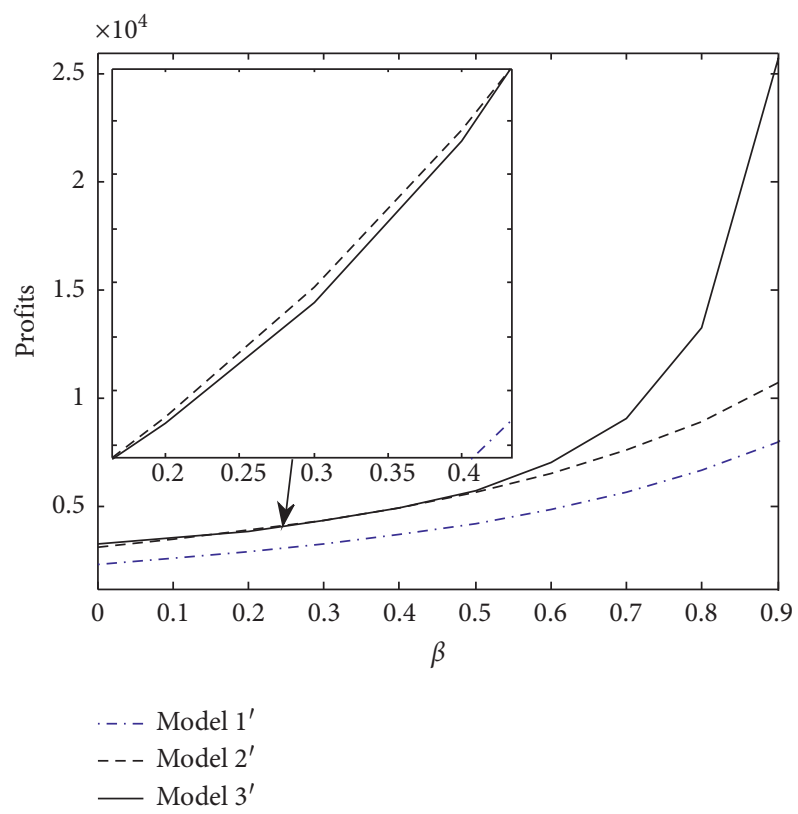

Figure 2: The effect of $\beta$ on competitorl's profit $(\Delta a=-50)$. 


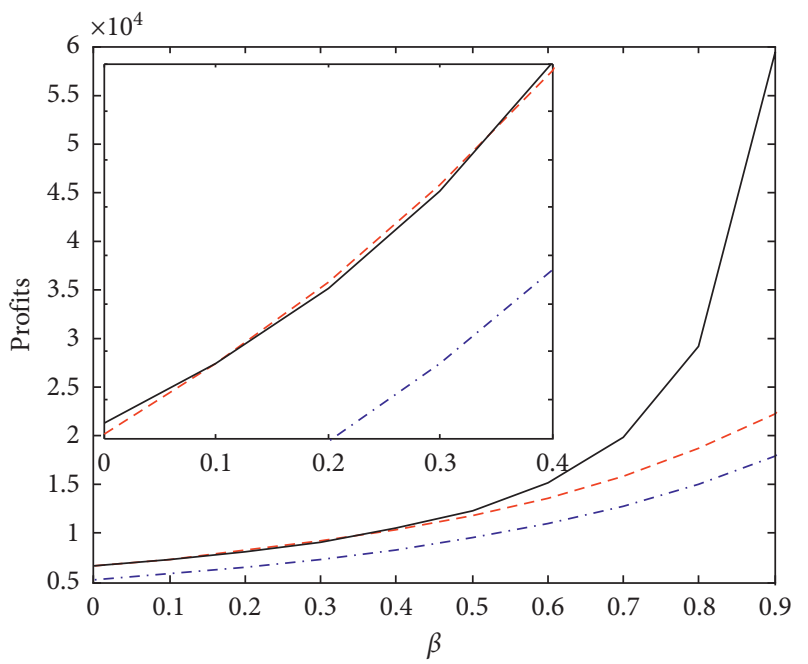

$$
\begin{aligned}
& \text {-. Model } 1^{\prime} \\
& \text { - - Model 2' } \\
& \text { — Model } 3^{\prime}
\end{aligned}
$$

FIgURE 3: The effect of $\beta$ on competitor2's profit $(\Delta a=50)$.

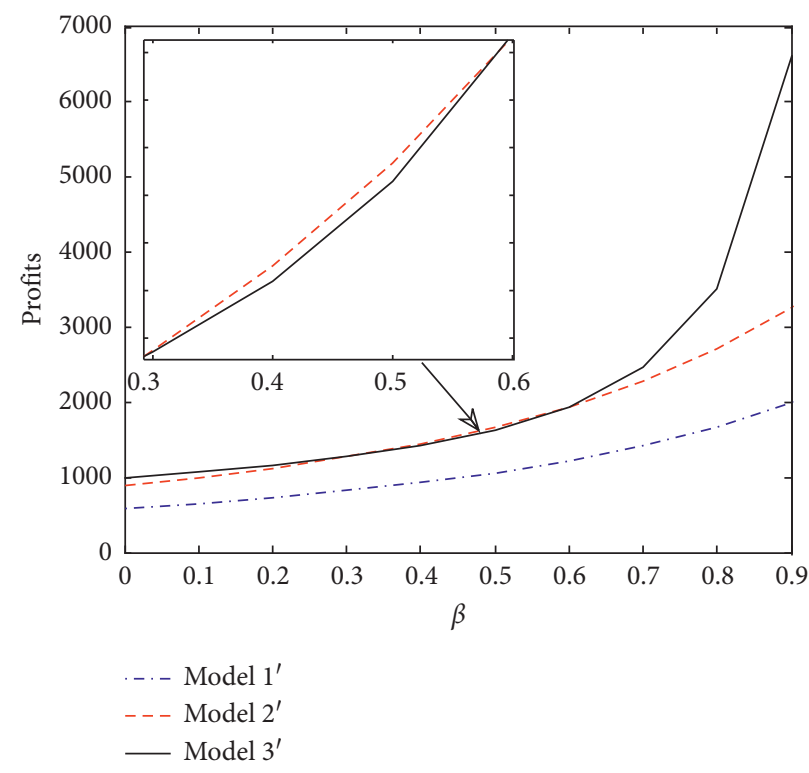

FIGURE 4: The effect of $\beta$ on competitor2's profit $(\Delta a=-50)$. 


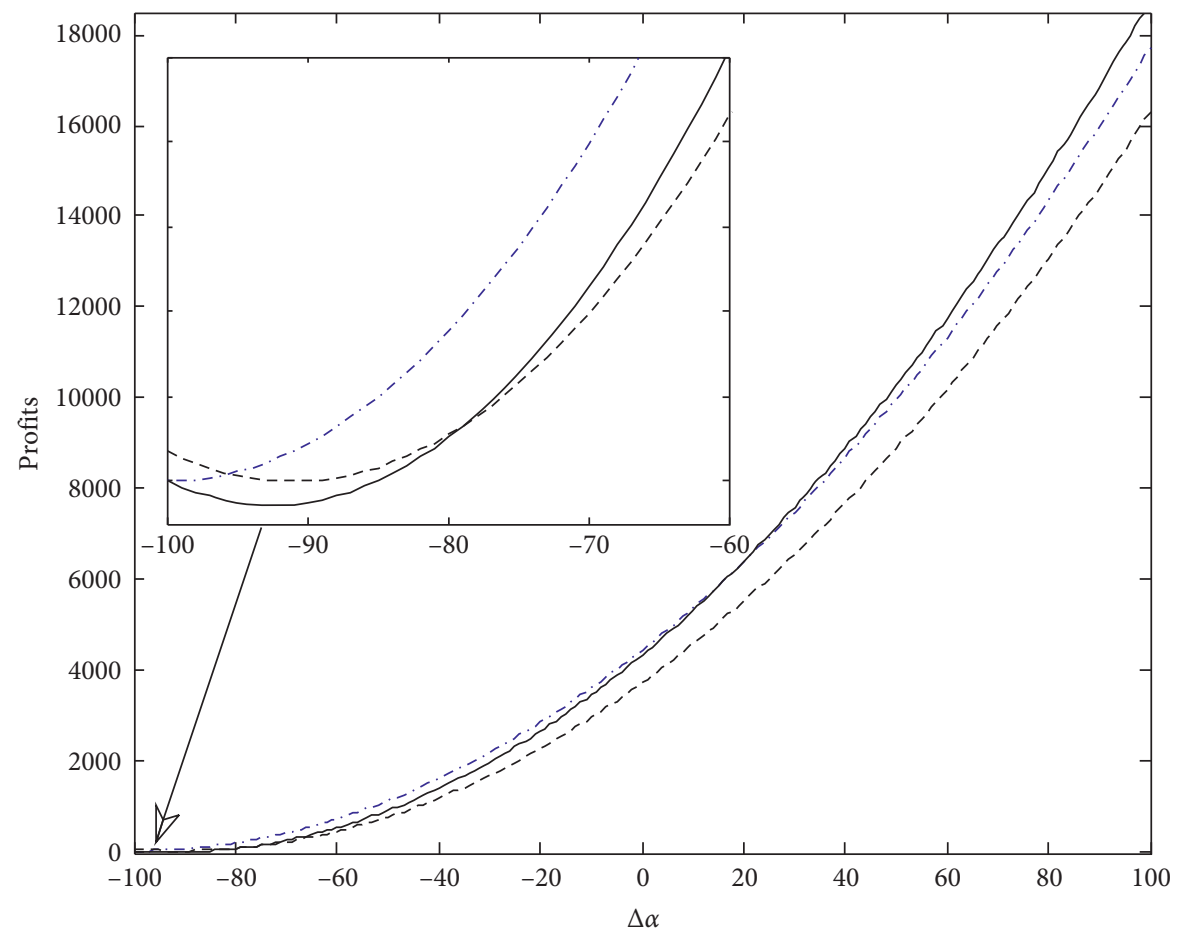

- - Model $1^{\prime}$

- - - Model 2'

- Model 3'

Figure 5: The effect of $\Delta a$ on competitorl's profit.

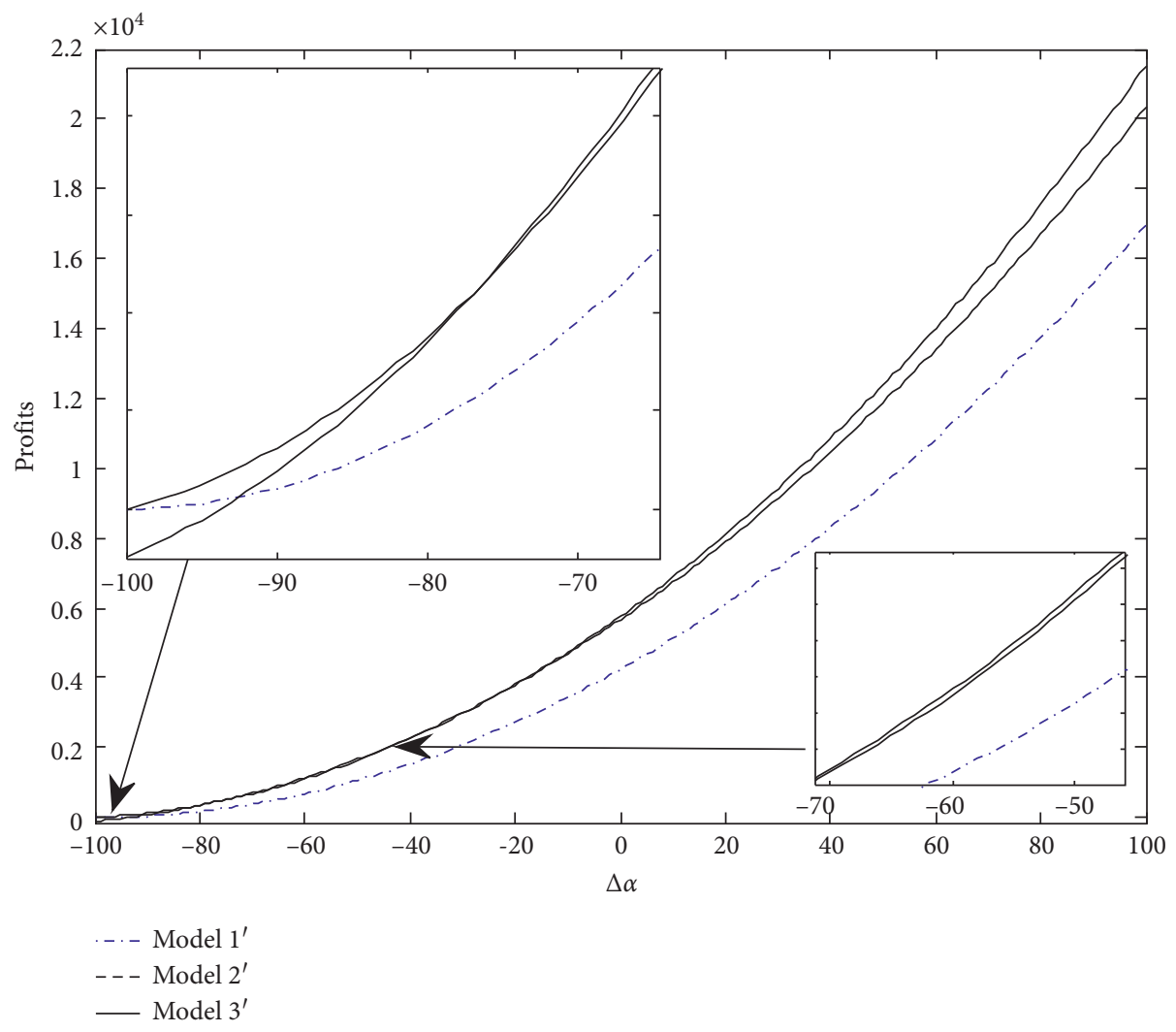

Figure 6: The effect of $\Delta a$ on competitor2's profit. 
competition and service capability sharing mode are better than centralized. It also shows that the value created by service capability sharing is better than centralized decisionmaking in some cases.

\section{Conclusion}

This paper mainly studies the mode selection of two competitors in the horizontal competition. This paper focuses on the introduction of price competition and service ability sharing mode, which is a business practice of service ability sharing between decentralized decision and centralized decision. The following conclusions were reached as follows:

(1) For competitor 1(2), changes in retail prices, service capability and demand disturbances $(\Delta a)$ are the same direction as those in the absence of demand disturbances.

(2) The demand disturbance has a greater impact on the service capability in the mode of centralized decision-making price and service capability than on the service capability in the mode of price competition and service capability sharing. It can be seen that if the demand disturbance occurs, the smoothness of service capability in the mode of price competition and service capability sharing is better than that in the mode of centralized decision-making.

(3) When the market price competition coefficient is moderate, the model of price competition and service capability sharing is more attractive to competitors, which is a very interesting conclusion, but also reflects that the value created by service capability sharing is better than centralized decision making in some cases.

(4) When a relatively small negative demand disturbance occurs, the price competition and the service capability sharing model have a slightly smaller impact on the profits than the other two models, when the competitor has the least profit loss under the price competition and the service capability sharing model, and the competitor will choose the price competition and the service capability sharing model by comparison. This is an interesting conclusion. In general, the case of centralized decision is slightly better than the other two decentralized decision cases, but the demand disturbance may be different.

This paper mainly considers the influence of demand disturbance on pricing and service ability. Under different circumstances, service firms can actively adjust their pricing and service ability in the market according to the positive and negative of demand disturbance to reduce the risk caused by demand disturbance. However, the cost change caused by demand disturbance is also very important to the core firms in the supply chain, and this aspect has not been considered in this article. So, the future study of analytical decision behavior can be deeply considering, furthermore, the demand disturbance and cost change.

\section{Data Availability}

The authors performed theoretical model research and then used numerical simulation to verify the theoretical results. These data are as follows: $a=100, r=0.5, k 1=3, k 2=2$, $\mathrm{pr}=15$, and $v=0.4$.

\section{Conflicts of Interest}

The authors declare that they have no conflicts of interest.

\section{References}

[1] J. Clausen, J. Larsen, A. Larsen, and J. Hansen, "Disruption management-operations research between planning and execution," Technical Report, Technical University of Denmark, Kongens Lyngby, Denmark, 2001.

[2] Y. Lan, Y. Li, and F. Papier, "Competition and coordination in a three-tier supply chain with differentiated channels," European Journal of Operational Research, vol. 269, no. 3, pp. 870-882, 2018.

[3] E. Cao, C. Wan, and M. Lai, "Coordination of a supply chain with one manufacturer and multiple competing retailers under simultaneous demand and cost disruptions," International Journal of Production Economics, vol. 141, no. 1, pp. 425-433, 2013.

[4] H. Du and Y. Jiang, "Strategic information sharing in a dynamic supply chain with a carrier under complex uncertainty," Discrete Dynamics in Nature and Society, vol. 2019, Article ID 4695654, , 2019.

[5] G. Ferrauto, R. M. S. Costa, P. Pavone, and G. L. Cantarella, "Human impact assessment on the Sicilian agroecosystems through the evaluation of Melliferous areas," Annali di Botanica, vol. 3, pp. 237-244, 2013.

[6] S. Pulvirenti, R. Maria Stefania Costa, and P. Pavone, "Francesco Cupani: the "scientific network" of his time and the making of the Linnaean "system"” Acta Botanica Gallica, vol. 162, no. 3, pp. 215-223, 2015.

[7] S. M. Ali, M. H. Rahman, T. J. Tumpa, A. A. Moghul Rifat, and S. K. Paul, "Examining price and service competition among retailers in a supply chain under potential demand disruption," Journal of Retailing and Consumer Services, vol. 40, pp. 40-47, 2018.

[8] A. Oke and M. Gopalakrishnan, "Managing disruptions in supply chains: a case study of a retail supply chain," International Journal of Production Economics, vol. 118, no. 1, pp. 168-174, 2009.

[9] S. Li, L. R. Liu, and Z. Gao, "Robust dynamic bus controls considering delay disturbances and passenger demand uncertainty," Transportation Research Part B: Methodological, vol. 123, pp. 88-109, 2019.

[10] E. Cao, J. Zheng, and Y. Ma, "Coordination of dual channel supply chain with demand disruptions," Chinese Journal of Management, vol. 11, no. 2, pp. 267-273, 2014.

[11] Z. Pi, W. Fang, and B. Zhang, "Service and pricing strategies with competition and cooperation in a dual-channel supply chain with demand disruption," Computers \& Industrial Engineering, vol. 138, Article ID 106130, 2019.

[12] K. Chen and T. Xiao, "Demand disruption and coordination of the supply chain with a dominant retailer," European Journal of Operational Research, vol. 197, no. 1, pp. 225-234, 2009.

[13] W.-G. Zhang, J. Fu, H. Li, and W. Xu, "Coordination of supply chain with a revenue-sharing contract under demand 
disruptions when retailers compete," International Journal of Production Economics, vol. 138, no. 1, pp. 68-75, 2012.

[14] M. Xu, X. Qi, G. Yu, H. Zhang, and C. Gao, "The demand disruption management problem for a supply chain system with nonlinear demand functions," Journal of Systems Science and Systems Engineering, vol. 12, no. 1, pp. 82-97, 2003.

[15] F. Chen, A. Federgruen, and Y.-S. Zheng, "Coordination mechanisms for a distribution system with one supplier and multiple retailers," Management Science, vol. 47, no. 5, pp. 693-708, 2001.

[16] K. Chen and T. Xiao, "Outsourcing strategy and production disruption of supply chain with demand and capacity allocation uncertainties," International Journal of Production Economics, vol. 170, pp. 243-257, 2015.

[17] D. Qiu-Lei, H. U. Xiang-Pei, and J. Yang, "Model of disruption management with consumption behavior in logistic distribution of perishable goods," Operations Research and Managementence, vol. 25, no. 6, pp. 68-74, 2016.

[18] T. G. Schmitt, S. Kumar, K. E. Stecke, F. W. Glover, and M. A. Ehlen, "Mitigating disruptions in a multi-echelon supply chain using adaptive ordering," Omega, vol. 68, pp. 185-198, 2017.

[19] T. Xiao and G. Yu, "Supply chain disruption management and evolutionarily stable strategies of retailers in the quantitysetting duopoly situation with homogeneous goods," European Journal of Operational Research, vol. 173, no. 2, pp. 648-668, 2006.

[20] K. Rahmani and M. Yavari, "Pricing policies for a dualchannel green supply chain under demand disruptions," Computers \& Industrial Engineering, vol. 127, pp. 493-510, 2019.

[21] A. Jabbarzadeh, B. Fahimnia, J. Sheu, and H. S. Moghadam, "Designing a supply chain resilient to major disruptions and supply/demand interruptions," Transportation Research Part B-Methodological, vol. 94, pp. 121-149, 2016. 